\title{
Juniper Pollen Hotspots in the Southwest
}

L. D. Bunderson ${ }^{\mathrm{a}}$, P. Van de Water ${ }^{\mathrm{b}}, \mathrm{J}_{\text {. Luvall }}^{\mathrm{c}}$, and E. Levetin ${ }^{\mathrm{a}}$

${ }^{\mathrm{a}}$ University of Tulsa, Tulsa, OK 74104, ${ }^{\mathrm{b}}$ California State University, Fresno, Fresno, CA 93740 , cNASA Marshall Space Flight Center Huntsville, AL 35812

Rationale: Juniperus pollen is a major allergen in Texas, Oklahoma, and New Mexico. While the bulk of pollen may be released in rural areas, large amounts of pollen can be transported to urban areas. Major juniper species in the region include: Juniperus ashei, J. virginiana, J. pinchotii, and $J$. monosperma. Pollen release is virtually continuous beginning in late September with $J$. pinchotii and ending in May with J. monosperma. Urban areas in the region were evaluated for the potential of overlapping seasons in order to inform sensitive individuals.

Methods: Burkard volumetric pollen traps were established for two consecutive spring seasons at 6 sites in northern New Mexico and 6 sites for two consecutive winter and fall seasons in Texas and Oklahoma. Standard methods were used in the preparation and analysis of slides.

Results: The Dallas-Fort Worth Metroplex is home to over 6 million people. It is adjacent to populations of J. pinchotii, J. virginiana, and J. ashei. Peak concentration near Dallas for J. ashei in 2011 was 5891 pollen grains $/ \mathrm{m}^{3}$ in January $7^{\text {th }}$. The peak date for $J$. pinchotii at an upwind sampling location in San Marcos, TX was November 1, 2010 and peak for J. virginiana at a nearby station in Tulsa, OK was February 20, 2011. Amarillo, TX is adjacent to J. pinchotii, J. ashei, and J. monosperma populations and may be subject to juniper pollen from September through May.

Conclusions: Considering the overlapping distributions of juniper trees and the overlapping temporal release of pollen, sensitive patients may benefit from avoiding hotspots. 